University of Montana

ScholarWorks at University of Montana

6-2015

\title{
Do you hear what I see? Assessing accessibility of Digital Commons and CONTENTdm
}

Wendy Walker

University of Montana - Missoula, wendy.walker@umontana.edu

Teressa M. Keenan

University of Montana - Missoula, teressa.keenan@umontana.edu

Follow this and additional works at: https://scholarworks.umt.edu/ml_pubs

Part of the Library and Information Science Commons

Let us know how access to this document benefits you.

\section{Recommended Citation}

Wendy Walker \& Teressa Keenan (2015) Do You Hear What I See? Assessing Accessibility of Digital Commons and CONTENTdm, Journal of Electronic Resources Librarianship, 27:2, 69-87

This Article is brought to you for free and open access by the Mansfield Library at ScholarWorks at University of Montana. It has been accepted for inclusion in Mansfield Library Faculty Publications by an authorized administrator of ScholarWorks at University of Montana. For more information, please contact scholarworks@mso.umt.edu. 


\title{
Title: Do you hear what I see? Assessing Accessibility of Digital Commons and CONTENTdm
}

\author{
Running head: Accessibility of Digital Commons and CONTENTdm
}

Abstract: This article discusses the accessibility of two content management systems, Berkeley Electronic Press' Digital Commons and OCLC's CONTENTdm, widely used in libraries to host institutional repository and digital collections content. Based on observations by a visually-impaired student who used the JAWS screen reader to view the design and display of digital objects in both systems, we provide a general overview of the accessibility of each system. We discuss potential suggestions for accessibility-related improvements, and we offer ideas for library administrators of these systems about how to maximize the back-end configurations for accessibility.

Keywords: accessibility, screen reader users, digital collections, Digital Commons, CONTENTdm, WCAG 2.0

\section{Authors:}

Wendy Walker, Digital Initiatives Librarian, Maureen and Mike Mansfield Library, University of MontanaMissoula, 32 Campus Drive, Missoula, MT 59812. E-mail: wendy.walker@mso.umt.edu

Teressa Keenan, Head, Bibliographic Management Services/Metadata Librarian, University of MontanaMissoula, 32 Campus Drive, Missoula, MT 59812. E-mail: teressa.keenan@mso.umt.edu

Received: September 25, 2014

Accepted: October 24, 2014

\section{Acknowledgements}

We would like to thank Aaron Page and Marlene Zentz for their generous participation in our study and for providing invaluable feedback about accessibility issues related to visual impairments and digital resources. 


\section{Do you hear what I see? Assessing accessibility of Digital Commons and CONTENTdm}

In March 2014, the President of the University of Montana (UM) signed a Resolution Agreement with the U.S. Department of Education, Office for Civil Rights (OCR) regarding the accessibility of electronic and information technology (EIT) at UM (UM/OCR, 2014). The resolution outlines a number of remedial actions, including the development of campus-wide EIT accessibility policies and procedures, a grievance procedure, EIT procurement procedures, and the provision of accessibility training to all UM faculty and staff. Furthermore, the resolution outlines an EIT corrective action strategy for library services and the library web site, for all UM web sites, for learning management systems, and for classrooms. Finally, the resolution agreement demands regular reports that describe how and what UM has accomplished in terms of addressing the specific requirements of the agreement.

While discussing the implications of the agreement for the library and, in particular, for digital collections and institutional repository content, we began to wonder about the accessibility of the content management systems (CMSs) that the library uses to host and to provide access to that content. After all, "digital accessibility requires that all aspects of the digital experience be accessible, i.e. the hardware, the operating platform, the software program or application, and the data itself" (Goldstein \& Niska, 2013). The Maureen and Mike Mansfield Library (ML) at UM has been hosting digitized special collections content in a local instance of CONTENTdm for several years. In addition, ML participates in the Montana Memory Project (MMP), a statewide digital collections initiative that employs a hosted instance of CONTENTdm. In late summer 2013, ML announced a new institutional repository built on Berkeley Electronic Press's (bepress) Digital Commons software.

A quick search of the literature indicated that most of the accessibility-related literature in the field of librarianship discusses web pages, documents, and library databases. We found only a few articles that specifically discuss digitized special collections content and found no articles that discuss or 
evaluate the software and platforms that are often used to host that kind of content. In an effort to answer our own questions about the accessibility of these systems and hoping to fill a gap in the literature, we decided to conduct research into the accessibility of bepress Digital Commons (DC) and OCLC's CONTENTdm (CDM) software. These software systems are widely used in libraries to host institutional repository and digital collections content, and they are the ones with which we remain most familiar.

Our familiarity with DC and CDM became important as we quickly learned that we had a lot to learn about accessibility and needed to expend most of our efforts in getting up to speed with accessibility basics. As librarians, we talk a lot about accessibility, but usually, we are talking more about availability than accessibility, particularly when we are referring to online digital content. In our discussions, we began distinguishing between availability and accessibility, using the latter term to encompass both online availability and the ability for all potential users to access the library's digital resources in an equivalent way.

Our research began with a review of both Section 508 of the Rehabilitation Act and the Web Content Accessibility Guidelines (WCAG), version 2.0, level AA in order to better understand what it means for digital resources to be accessible. (The WCAG 2.0 standards are specifically referenced in the UM-OCR Resolution Agreement.) We perused web sites such as WebAIM (http://webaim.org) for both introductory and more advanced information about general accessibility issues related to digital resources.

With accessibility basics in hand, we set out to answer our initial, seemingly simple queries: How accessible are the CMSs we use for our institutional repository and digital collections content (DC and $(\mathrm{CDM})$ ? Is one system generally more accessible that the other? This paper presents our initial findings regarding the basic accessibility of bepress' Digital Commons and OCLC's CONTENTdm. We outline the positive features of each system as well as the issues encountered with each system during the course 
of our study. We provide a general comparison of the two systems in terms of accessibility and discuss suggestions for improvements to each system as well as issues to consider while configuring and administering each system.

\section{Literature Review}

Library and information science (LIS) literature on accessibility is not as prominent as it is in some other disciplines. However, legislation such as 1990's Americans with Disabilities Act (ADA) and Section 508 of the Rehabilitation Act require higher education institutions and federally funded organizations to make their resources and services available and accessible to patrons with disabilities. This legislation has not been overlooked by the profession, and many articles that address issues related to library accessibility also evaluate the meaning and impact of federal disability laws on library collections and services (Schmetzke \& Comeaux, 2009; Tatomir \& Durrance, 2010; Southwell \& Slater, 2012; Stewart, Schmetzke, \& Narenda, 2005; Providenti \& Zai, 2007). Fulton (2011) is one of the few authors to systematically examine state web accessibility statutes as they relate to libraries.

Other researchers have studied accessibility related to electronic resources, such as library web pages and purchased or licensed library databases; services to people with disabilities; and advocacy (Hill, 2013). Many of these studies contain an account of access challenges and recommendations supported with little empirical research (Davies, 2007; Hill, 2013). Davies (2007) and Hill (2013) both identify a need for more research. Hill (2013) advocates for a "stronger presence of people with disabilities participating in the research, a focus on increasing the quantity and quality of qualitative and quantitative research, and a greater understanding of the importance of the social and attitudinal aspects of accessibility" (p. 141).

A number of studies have focused on the accessibility of North American library and libraryschool web sites. Schmetzke and Comeaux (2009) provide an overview of the status and trends from 2002-2012; they conclude that "despite improvements over the past 4 years, library and (even more so) 
LIS school web sites (particularly those in the U.S.) still tend to contain many accessibility barriers" (p. 150). Some researchers provide reviews of current practices and tools related to library web-page accessibility (Cervone, 2013), while others focus on specific types of libraries (Kahl \& Williams, 2006). Some focus on web accessibility at the state or institutional level (Providenti \& Zai, 2007). It is not surprising that so many library studies have focused on the accessibility of library web pages. Library web-page accessibility is an important topic of inquiry, and established protocols for ensuring compliance with ADA mandates, accepted standards such as WCAG, and established tools for automated website checking help define the research parameters for this topic.

Accessibility of library databases is also well-represented in LIS literature. A number of studies investigate the accessibility and usability of these online resources for people using assistive technologies. All of these indicate that while most indexes and databases are now largely compliant with common accessibility standards and permit the performance of common search tasks, their actual userfriendliness for people with disabilities tends to be low (Riley, 2002; Stewart et al., 2006; Byerley, Chambers, \& Thohira, 2007). Other studies build on the accessibility evaluation process and provide best practices for enhancing access to electronic resources (Tatomir \& Durance, 2010; Tatomir \& Tatomir, 2012).

Digital collections are also being examined by researchers interested in accessibility. Robinson's dissertation (2004) was the first to address the accessibility of online digital image collections created by libraries, museums, and archives in the UK. She sent questionnaires to both visually impaired users of the digital image collections and to the staff who maintain the collections. She reported that while some of the collections are accessible, barriers exist. She also highlighted some of the difficulties faced by institutions that create digital collections. Another unique study involved a close look at the accessibility of digitized special collections content via the use of screen readers (Southwell \& Slater, 2012). Similar to other studies, the authors discovered a number of common barriers to screen-reader access of the 
digitized content. While their study focused on digitized textual content within online CMSs and did not focus on a particular CMS, a number of the institutions that they studied use CDM (25 of 69) to disseminate their digital collections.

There are a number of case studies of CDM covering the creation of various digital collections, but none of these address accessibility specifically (Daniels, 2009; Valentino \& Shults, 2012). There are also a few general usability studies focused on CDM. These published user studies do not address accessibility of the product by disabled users (Kramer, 2005; Dickson, 2008). So while Robinson (2004) and Southwell and Slater (2012) have looked at the accessibility of digital collections content, and others have conducted general usability studies of CDM, no one has yet specifically investigated the accessibility of DC and CDM.

Looking beyond the scope of LIS literature, we found a number of studies that explored the web experience of blind users. These studies focused on the challenges faced by blind users of the web and identified the most common frustrations of screen reader users (Lazar, Allen, Kleinman, \& Malarkey, 2007). Other studies focus on tactics used by screen-reader users for specific tasks such as skimming (Ahmed, Borodin, Puzis, \& Ramakrishnan, 2012), browsing (Bigham, Cavender, Brudvik, Wobbrock, \& Lander, 2007), and navigating (Vigo \& Harper, 2013) web pages. Interestingly, a number of these studies observed and highlighted the users' experience of "cognitive overload," which occurs while users try to understand the browser, the website, and the screen reader simultaneously, all while being forced to hear repetitive information across pages (Xie, Babu, Jeong, Joo, \& Fuller, 2014; Ahmed et al., 2012; Theofanos \& Redish, 2006).

\section{Methodology}

This study is intended to be a preliminary exploration into the basic accessibility of the library's instance of DC hosted by bepress and an OCLC- hosted instance of CDM. A blind student volunteered to help us evaluate the systems by browsing pre-selected pages and describing his initial observations 
about the interfaces. We were interested in the basic functionality and presentation of the various types of digital objects in each system. We did not conduct a usability test to explore the ease and/or success of searching and retrieval. We wanted to know if a student could understand the display and presentation of the digital objects, based on each system's design and structure, while using a screen reader.

We chose a sampling of objects that represented the most common types of resources found in each repository and that provided the student with the opportunity to view all of the content structures available in each system. To the extent possible, we also tried to select parallel page types for comparison. For example, we asked the student to review the home page in both systems. We conducted the interview in a location chosen by the student. He used his personal laptop computer and ran Firefox version 28.0.1 and the JAWS screen reader, version 15. We used Camtasia Relay version 4.3.1 to record the interview. We set up a second laptop and used a Canon EOS 60D camera to record the two laptop computer screens side by side so we could learn how the basic experience of a blind student using JAWS differed from the experience of a sighted person.

We then scheduled two interview sessions with the student, each session dedicated to a single system. We followed a "think-aloud method" of collecting data (Someren, Barnard, \& Sandberg, 1994). The interviews were designed to be open in nature, with no pre-planned questions other than asking the student to look at the pre-determined pages in the repositories and to tell us what he thought of his experience as he browsed the pages. We provided introductory background information describing the purpose of each repository but did not discuss in detail the content prior to his initial exploration. If the student became confused or stuck, we provided assistance by explaining what we could see on the screen and describing the visual structure of the page. We also asked questions to clarify our understanding of his explanations.

The specific Digital Commons pages reviewed by the student included: 
- ScholarWorks (http://scholarworks.umt.edu): The home page of our instance of DC.

- Browse by Research Unit, Center or Department (http://scholarworks.umt.edu/communities.html): This is a commonly-used menu/navigational page within DC.

- Flathead Lake Seismic Survey (http://scholarworks.umt.edu/flathead/): This is a home page for a DC book gallery.

- Flathead Lake Seismic Survey: C. Field-Recorded Seismic Sections (http://scholarworks.umt.edu/flathead/2/): This is an item-level page within a DC book gallery.

- Anthropology Faculty Publications (http://scholarworks.umt.edu/anthro pubs/): This is a home page for a DC series.

- Theses, Dissertations, Professional Papers: Spatial regression methods capture prediction uncertainty in species distribution model projections through time (http://scholarworks.umt.edu/etd/905/): This is an item-level page within a DC ETD series and includes additional files.

- The Oval (http://scholarworks.umt.edu/oval/): This is the home page for a DC journal.

- Rural Health Workshop 2013: Schedule (http://scholarworks.umt.edu/rural health/2013/): This is a conference-schedule page within a DC event community.

- The Student Research Experience (http://scholarworks.umt.edu/studentresearch/). This is a home page for a DC image gallery.

- The Student Research Experience: Levi McClelland's Research Experience at the University of Montana (http://scholarworks.umt.edu/studentresearch/1/): This is an item-level page within a DC image gallery.

- Smokejumpers Oral History Project: Interview with Watson "Java" Bradley on his experiences as a Navajo smokejumper (http://scholarworks.umt.edu/smokejumpers/26/): This is an item-level page within a DC book gallery that includes an audio file and a transcript. 
The specific CONTENTdm pages reviewed by the student included:

- Montana Memory Project (http://mtmemory.org): This is the CDM home page for the MMP.

- Boone and Crockett Club Records

(http://cdm16013.contentdm.oclc.org/cdm/landingpage/collection/p16013coll13): This is a collection landing page within CDM.

- Early Montana Histories collection browse

(http://cdm103401.cdmhost.com/cdm/search/collection/p15018coll38/collection/p15018coll38):

This page within CDM allows users to browse all of the items within the collection.

- History of Montana. 1739-1885

(http://cdm103401.cdmhost.com/cdm/ref/collection/p15018coll38/id/396): This is an item-level title page within a compound object. The digital object was uploaded as .jpg files without transcripts.

- Correspondence to Mr. Marshall E. Dimock from W. F. Watkins (http://cdm16013.contentdm.oclc.org/cdm/compoundobject/collection/p16013coll22/id/123/rec/9 ): This is an item-level page within a compound object. The digital object was uploaded as .jpg files with .txt transcript files.

- An American Game Policy (http://cdm16013.contentdm.oclc.org/cdm/ref/collection/p16013coll13/id/1073): This is an itemlevel page for a single item. The digital object was uploaded as an OCR'd PDF file and was not converted to a compound object. For the purposes of testing, this digital object was larger than 20 $M B$, so rather than provide the document inline, CDM provided a link for the user to download and view the file outside CDM. 
- Boone and Crockett Club Memorandum for the Solicitor

(http://cdm16013.contentdm.oclc.org/cdm/singleitem/collection/p16013coll13/id/937/rec/5): This is an item-level page for a single item. The digital object was uploaded as an OCR'd PDF file and was not converted to a compound object.

- Aftermath of a snow in Milltown

(http://cdm16013.contentdm.oclc.org/cdm/ref/collection/p15018coll37/id/2376): This is an itemlevel page for a single-item image in CDM.

- An audio file with transcript from the Mansfield Papers collection. The audio file was uploaded as a .mp3; the transcript was uploaded as a single, multiple-page, OCR'd PDF. The files were uploaded together as a compound object. This object was loaded for testing purposes and is not publicly available.

Interview tapes from both sessions were transcribed and analyzed. We then examined parts of the source code using the view source and/or inspect element functionality of the Chrome and Firefox browsers and compared some of the student's comments with the source code to find out if the student's observations matched the code. If, for example, the student said that there were no headings or that an alt-tag was missing, we checked for the presence or absence of these elements in the code.

\section{Results}

Digital Commons

Digital Commons fared relatively well in our study. The student reported features that he both liked and disliked as he reviewed various pages and all of the content structures within our local instance of DC. In particular, he liked that DC:

- Does not use Flash 
- Uses headings for easy navigation of each page. For example, series-item lists are relatively easy to navigate because they include headings such as, "submissions from [year]", which are tagged as heading $4(<\mathrm{h} 4>)$.

- Uses descriptive links

- Provides keyboard shortcuts that are not specifically tied to a screen reader, which provides good accessibility for screen-reader users and non-screen-reader users who prefer the keyboard to the mouse

- Uses a vertical bar to separate the names of disciplines associated with an item; the student stated that vertical bars are well understood symbols and are frequently used in social media

- Displays metadata in a way that is generally easy to locate and understand

- Offers breadcrumbs as an additional navigational tool

- Presents conference schedules in an easily navigable format

- Provides audio and video files for download, to be played on the user's machine

This list does not comprise all of the accessible features of the software, but all of these features assist visually impaired users as they use a screen reader to make sense of DC pages and the repository content.

During the test, the student also encountered difficulties.

- The homepage graphic needs better alternative text (alt-tag); currently, the alt-tag appears to be the filename.

- The student opened a links list on the communities page, which lists the various "collections" within the repository. The links list included a hashtag (\#) symbol after each link. The screen reader read the symbol as "link number." So the student heard, "link college of education and human sciences; link number; link communicative sciences and disorders; link number; link communicative sciences and disorders faculty publications; link number; etc." 
- While he liked that DC offers breadcrumbs for navigation, he did not like their placement on the page. They are typically located between heading one and heading two. Heading one is the name of the repository and is repeated on every page of the repository, so a screen reader user may quickly decide to jump immediately to heading two, thereby skipping the breadcrumbs altogether. It is possible that the user may never encounter the breadcrumbs and would thereby miss a potential navigational aid.

- Similarly, when the student reviewed the home page for a journal, he did not immediately understand what kind of content was represented on the page because the journal description is located between headings.

- When the student opened a PDF document within his browser, the screen reader was unable to correctly read the document. Once the student downloaded the document to his computer and opened the PDF in Adobe Reader, the screen reader correctly read the document. The student remarked that PDFs often do not "read" well when opened within the browser, so while this problem is not specific to DC, it is worth remembering because a lot of the content within DC repositories will be in PDF documents.

- On item-level pages, the student reported that title fields of individual items do not have a heading associated with them. The series title is a heading 2 , and the rest of the metadata fields are marked as heading 4 .

- The location of downloadable files differs from structure to structure. The inconsistency of the placement of the files across the structures makes it difficult for screen reader users to remain oriented as they navigate the repository.

- When reviewing an item-level page within a book gallery, the downloadable files just "appear" in the middle of the metadata. The placement of these files interrupts the screen reader user's 
perusal of the metadata and undermines the user's ability to use all of the metadata as context for and before encountering the downloadable content.

- When a downloadable file is large, DC administrators can ask bepress support to provide a note to users on the metadata page, indicating that the file is large and may take several moments to download or open. This note visually appears to the left of the box containing the downloadable files; however, for a screen-reader user, this note is read after all of the other metadata has been read, so it no longer appears contextually relevant.

- When viewing a landing page for a book gallery, users have the option to view item thumbnails in a View Slideshow mode. This mode did not work well with the student's screen reader.

- When reviewing an item-level page within a series, the student wanted to download the associated content. He could not quickly find the download button, so he brought up a links list in his screen reader, assuming that the download button would be listed as a link. He pressed the ' $D$ ' key but did not find the download button. In some instances in $D C$, the download button includes the symbol of a downward-pointing arrow in front of the word "download."

Presumably, this symbol serves as a visual indicator of the download action, but in the links list, the symbol renders as a space before the letter ' $D$ ' in the word "download." The student eventually found the link in his list, but because of the space before the letter ' $D$,' the word "download" did not sort alphabetically in his list. In other words, the student was unable to effectively use the links list in order to locate the download link.

- When an item includes supplemental files, they are listed at the bottom of the item page by default. These files could be easily missed by screen-reader users. First, the "additional files" label does not appear to be marked as a heading so cannot be located via a list of headings. Second, the additional files are links, but in terms of reading order, a screen reader reads these links after reading a "Follow" [the author] link at the top of the page, so there is no context for 
these additional files. A screen-reader user who finds them in a links list will not have context for them either as the links will simply be file names, which may or may not be descriptive.

- The student did not find row and column headers when reviewing a conference schedule. He eventually determined that the schedule was relatively easy to navigate, but row and column headers would have shortened the time it took him to make that determination.

- When reviewing the landing page for an image gallery, the student wondered why the item titles are not links. Users have to click the thumbnail images in order to access item-level metadata. While we also find this peculiar, it is particularly awkward for visually-impaired users because a screen reader announces the linked image before it reads the item title. So the user hears the title then has to navigate backwards to find the link to click in order to access the item-level content.

- Once on an item-level page within an image gallery, the primary image, which is embedded in the metadata, does not appear to have an alt-tag.

- The download buttons on an item-level page within an image gallery are recognized by the screen reader after the image gallery title heading. The student found the placement of these download buttons surprising, and he was not entirely sure what he would be downloading if he clicked on them.

The student eventually figured out how to work around or safely ignore many of the issues noted here. In other words, these issues did not prohibit him from accessing content in the repository; however, many of them caused the student both confusion and delay. In a study on "What frustrates screen readers users on the Web", Lazar et al. (2007) noted that "blind users reported losing, on average, $30.4 \%$ of time due to...frustrating situations" (p. 247). After observing the student in our study struggle with some of the issues noted above, this result is not at all surprising. 


\section{CONTENTdm}

CONTENTdm, as configured at the time of this study, received mixed reviews. The home page and the collection landing page both fared relatively well while the object-level pages varied from slightly difficult to completely unusable. The student reported features that he both liked and disliked as he reviewed various pages and all of the content structures within the MMP instance of CDM. In particular, he liked that CDM:

- Does not use Flash

- Uses headings for easy navigation of top-level pages. For example, the Homepage and the collection landing pages are relatively easy to navigate because they include headings such as "All collections" and "About this collection," that are marked up as headings in the code.

- Uses descriptive links

- Includes one clearly labeled form field (search box) enabling the user to easily find and enter a search query

- Presents a simple, uncluttered collection landing page

- Includes alt-tags for most images

- Provides audio and video files for download, to be played on the user's machine

- Employs properly working dropdown (combo) boxes to narrow searches. The screen reader clearly indicated if the list is expanded or collapsed.

- Provides PDF image controls such as zoom, download, and print, which are clear and easy to use (formatted as a button which improves navigation).

This list does not comprise all of the accessible features of the software, but all of these features assist visually impaired users as they use a screen reader to make sense of CDM pages and the collection content.

During the test, the student also encountered difficulties: 
- The default focus is set to the search box. While this made sense to him if he were using the search functionality, it became tedious and even caused confusion as he browsed through the collections. Every time the screen refreshed the focus returned to the search box. This required him to realize where he was and then re-navigate to the place on the page in which he was interested. On more than one occasion, the student got "stuck" in the search box. He became confused about why the browser was not responding as he expected and it took him time to figure out he needed to move out of the box before he could continue.

- The top-level navigation bar is located above the search box and above the Level 1 heading. The student did not discover this navigational aid until it was pointed out to him. He said that most likely, he would never have noticed it on his own because of its placement on the page. He would have had to arrow up from the search box or from the Level 1 heading in order to find it, which would be an unintuitive move.

- Confusing link descriptions that were not explicit enough to be easily understood. For example, on the home page there is a brief description of each collection followed by a link labeled "more ..." The student's initial response was "more what?" As another example, when browsing a collection that contains more items than can be displayed on one page, the links to more results pages read "1 2 ... 62" The student was able to figure out what was going on, but it took a bit of effort and guesswork.

- Inconsistent or less detailed heading structure on object-level pages. Once beyond the home page and collection landing page, the student had difficulty navigating and understanding the structure of the pages. He often became confused because he couldn't determine if he was looking at an actual object, metadata, or navigational areas.

- Occasional missing/undescriptive alt-tags. The student was confused when the screen reader read what sounded like "Graphic P16013:13" and assumed that the alt-tag was missing. Later 
examination of the source code revealed that the image does have an alt-tag (alt="p16013coll13"); it is just meaningless to the user.

- Checkboxes on the browse-a-collection page are not tied to their labels. When navigating from one checkbox to another, the student indicated that there was nothing to describe the purpose of the checkbox. After some experimentation, he discovered that if he went to the checkbox and then tabbed forward or backward, he would get to the text description. He indicated that this was an awkward and unintuitive workaround. Additionally, the save-to-favorites checkbox repeated this phrase both before and after the checkbox, so he had to tab twice to get to the text description to hear what he was saving to his favorites.

- The different areas of the browse-collection and compound-object pages are easy to distinguish visually but are complicated and unintuitive for a screen-reader user. The student was unable to understand what he was viewing without assistance from us. On the browse-a-collection page, the student got stuck in the left-hand panel, where he could select which collections to include or exclude in a search. He misunderstood that this list of collections was not the information in the main content area of the page. On the compound object pages, he repeatedly got stuck in the table of contents panel and was unable to actually find and interact with the digital object.

- Thumbnail images did not appear as images. To the student they looked like links, and he commented that he wasn't sure what they were linking to; he thought they might be authors' names. Examination of the source code revealed that the images link to the actual item. The alttags contain the text of the item title. He was interacting with photographs of people. The titles given to these photographs included simply the name of the person in the photograph.

- Expandable menu items in the compound-object, table of contents panel were not functioning well with the JAWS screen reader. The screen reader indicated only that the menu items are 
clickable. When clicked, the focus was moved out of that area without the student realizing it, and he was unable to determine where he was on the page.

- Hyperlinked metadata terms were difficult to understand. One of the collections that the student reviewed for this study did not utilize the controlled vocabulary functionality built into CDM. Thus the word "link" was read by the screen reader before each word in the description and in the subject fields, making the content unintelligible. The fact that the student didn't realize that he was in the metadata fields and was unaware of the capability of using hyperlinked metadata to search for other similar items added to his confusion.

- Transcript text not rendered as plain text. Compound objects created by loading .jpg images with accompanying .txt transcript files allowed the screen reader to access the text; however, JAWS did not interpret the text as plain text and repeatedly inserted the word 'clickable' throughout the text. This made understanding the actual content problematic. When the student tried to click on the words, they did not actually link to anything.

- Viewing the text of a PDF object within the browser window is difficult. Similar to the results of viewing the compound-object transcripts, JAWS did not interpret the text as plain text and repeatedly inserted the word 'clickable' throughout the text. The student was able to download the PDF and view it in the native Adobe interface on his computer.

- Download option is neither a button nor an actual link, so a screen reader user cannot use a links list or the "B" key (to get to it as a button) to locate it. JAWS read the download button as a "clickable" object, but the link worked when the student clicked on it.

- Unidentified, "ghost" metadata field on the item-level page for a single item PDF. The field was not labeled, and it only allowed the student to enter a single character. Neither the student nor the researchers were able to identify where/what this field was. 
- On the item-level page for the photograph, the student had a hard time understanding that the metadata description he was hearing was describing a photograph.

- The student had difficulties navigating between the audio player and the accompanying transcript.

The issues noted here varied in significance and impact on the student's ability to use and understand the digital objects depicted in the CDM interface. The student was unable to figure out how to work around or safely ignore many of the issues, and in some cases, he was essentially prohibited from accessing the resources. The student was able to use and understand the home page and the textbased objects configured as single-item PDFs; however, he was unable to identify the nature of the photograph without our assistance. With the exception of the audio file and accompanying transcript, resources configured as compound objects were particularly problematic and were determined to be completely inaccessible to this student.

\section{Discussion}

This study provided us with a single, visually impaired student's initial impressions of DC and CDM. The student did not specifically test the experience of browsing these systems; nor did he attempt to conduct searches in them. Instead, he provided observations about the accessibility of the basic structures within each system. We acknowledge that there are limitations inherent in this kind of study in that it is based on subjective feedback from a single individual.

Other factors complicate the widespread application of the study's results as well, including the technologies used (the browser, the assistive technology), the ability of the student to maximize use of the assistive technologies used, and the student's personal methods for navigating online resources. As these factors differ among individuals, the specific results outlined in the previous section would likely vary given the inclusion of additional visually impaired participants. 
So while it is important not to overgeneralize the student's observations about DC and CDM, we believe that we can provide a basic summary of the relative accessibility of each system; suggest some changes that the vendors might make in order to improve the accessibility of each system; and suggest configuration settings that collections/system administrators might consider as they work with DC and CDM.

\section{Digital Commons and CONTENTdm: Basic Accessibility}

While it is difficult and probably unnecessary to directly compare the systems against each other due to their very different structures, it is instructive to consider how they compare in terms of meeting basic accessibility requirements. An initial review of each system's Voluntary Product Accessibility Template (VPAT), a form that allows “content vendors [to] self-disclose their own products' accessibility performance" (Tatomir \& Tatomir, 2012, p. 41), indicates that both DC and CDM are basically compliant with Section 508 standards (bepress, 2011; OCLC, 2011). Furthermore, both systems share several features important to basic accessibility:

- Both use headings for structure, at least to some degree

- Both use descriptive links in many or most places

- Both allow files to be downloaded for viewing/use on the user's machine

- Neither system uses Flash

These features, particularly headings and descriptive links, are frequently used by screen reader users. As Robinson (2004) notes,

Sighted people can instantaneously jump from looking at one part of the computer screen to another and can quickly get an overview of a Web page's content. A blind user cannot do this. One way for blind users to get an overview of a Web page is to listen to the headings, and most screen readers have a feature that allows users to jump from heading to heading" (p. 28). 
Screen readers can also display a list of links on a page, and users can jump from link to link. Together, all of the features listed above help screen-reader users understand the context and structure of the content on a page, navigate to various areas on or away from a page, and utilize their own software to view downloadable content without the need for prohibitive inaccessible players, plug-ins, or applications. The consistent use of headings, descriptive links, and clearly labeled page elements across all the pages of a system such as DC or CDM assists the screen reader user with navigation and orientation within the system, reducing their cognitive load, defined "as the level of mental energy required to process a given amount of information" (Cooper, 1990, p. 108) and allowing them to focus on accomplishing tasks related to research and learning rather than on trying to figure out where they are in the system or how to work around a technical difficulty.

Unfortunately, the student in our study encountered several issues in both systems. Most of these issues were due to an inconsistent or repetitive use of headings, poorly described links, and inadequately marked page elements, although other issues surfaced as well. As a result, some pages and content structures within DC and CDM are more or less accessible than others. The bottom line, however, is that even though the student in our study encountered some of the same kinds of problems in $\mathrm{DC}$ and $\mathrm{CDM}$, the problems he encountered in CDM related to poorly labeled page elements (i.e., checkboxes, page number and "next page" links); a lack of consistent headings structures; the complex structure and reading order of compound objects; issues with the content panel in a compound object; and difficulties navigating to item-level metadata led us to conclude that CDM is less accessible than DC. The problems he encountered in both systems were frustrating and time-consuming, but the issues he faced in CDM actually prohibited him from understanding and accessing content and associated metadata. 


\section{Suggestions for Improvements}

Based on the feedback from the student in this study, we suggest that bepress and OCLC consider the following suggestions for improvements related to accessibility. We make these suggestions in support of the overall spirit of the WCAG 2.0 guidelines, which aim to make digital content fully accessible through well-structured web pages and adequate contextualization (World Wide Web Consortium [W3C], 2008). More specifically, these suggestions support the intention of the guidelines to ensure "that all information is available in a form that can be perceived by all users, for example...presented in a simpler visual layout" (W3C, 2008, Guideline 1.3); that the "purpose of each link can be determined from the link text alone or from the link text together with its programmatically determined link context" (W3C, 2008, Guideline 2.4.4); and that online systems provide sufficient "ways to help users navigate, find content, and determine where they are" (W3C, 2008, Guideline 2.4). It should be noted that we plan to contact both companies to discuss these suggestions.

\section{Digital Commons}

- Allow an institution to provide descriptive alt-text for the homepage image or, if purely decorative, provide an empty alt-tag so that screen readers ignore the image.

- Confirm that the links list on the communities page does not include a hashtag (\#) symbol after each real link.

- Consider the incorporation of regions and place the breadcrumbs in the navigation region in order to avoid the current situation that places the breadcrumbs between headings 1 and 2 . The student remarked that the use of regions would be useful for navigation. Regions, or ARIA Landmarks, "are attributes you can add to elements in your page to define areas like the main content or a navigation region" (ARIA Landmarks, n.d., para. 1). The student stated that landmarks are not widely used and that not all screen readers can use them, but he thinks they will be more widely used and actionable by screen readers in the near future. 
- Position the journal description on a journal homepage so that the description does not fall between headings.

- Consider marking up item titles on item-level pages as Heading $3(<\mathrm{h} 3\rangle)$, given both the title's importance in distinguishing specific content and because the item-level page does not appear to include a Heading 3.

- When reviewing an item-level page within a book gallery, the downloadable files just "appear" in the middle of the metadata. If it is not feasible to place the files elsewhere in the reading order, consider including a label or text that indicates that the screen reader user can now expect to encounter downloadable files. Further, when institutions have asked for a "large file size" note, it would be useful if this note was encountered by a screen reader near the downloadable files.

- Review the "View Slideshow" option, and ensure that it is compatible with screen readers.

- Some download buttons include an arrow symbol before the letter D in the word "download." Remove this symbol as it interferes with the links list in a screen reader.

- Consider providing better labeling or context for additional files that display at the bottom of the page after the last metadata field.

- Make sure that conference schedule tables have row and column headers. Would it be possible to automatically generate an Excel version of the schedule that could be made available to screen-reader users?

- Consider hyperlinking item titles on image-gallery landing pages.

- Make sure that images that appear in-line with metadata include alt-text. 


\section{CONTENTdm}

- Consider changing the default focus from the search box to the main heading on each page. The student's "recommendation would be that it should land on whatever main heading that you have got going on, on the page" (A. Page, personal communication, March 31, 2014).

- Ensure that all links are descriptive. For example, when a user has the option to click "more" to read a complete collection description, the link for "more" should be something like "more about this collection."

- Create clear and consistent heading structures on each page to make it easier for users to understand where they are in the system. Examination of the source code after the interview revealed that there are headings throughout all pages, but perhaps additional coding could be added to clarify the meaning of each heading. Two or three different level headings on the same page often have the same descriptive text but refer to different things functionally, i.e., compound-object title versus page title.

- Provide meaningful alternative text for all images within the system.

- Make sure that checkboxes are correctly and descriptively labeled.

- The student in our study encountered myriad issues with compound objects, as did sighted users in a 2008 general CDM usability study: "The compound object interface needs an almost complete overhaul in order for it to be usable" (Dickson, p. 372). Despite an overhaul to the compound object structure after Dickson's study, her finding remains relevant. We recommend that OCLC conduct usability testing with a variety of users, including screen-reader users, to identify issues and solutions related to compound objects.

- Make hyperlinked metadata configurable at the field level so that administrators could choose, for example, to hyperlink controlled subject terms in the subject field but disable hyperlinking of title and description fields. 
- The student in our study had a difficult time contextualizing item-level metadata. We suggest that OCLC conduct additional testing with screen-reader users to determine solutions for providing better context and navigation that would facilitate screen-reader users' orientation within the system.

- Investigate issues related to the repeated encounter with the word "clickable." The student encountered this announcement in several circumstances, and it was always problematic.

- The student noted that the download button on an item-level page would have been much easier to find if it were a button or an actual link because he could have used navigation shortcuts to get to it. Consider making the download button a button or a link.

- Consider incorporating regions to make navigation among navigational tools, digital objects, metadata, and item structure easier and more intuitive.

\section{Suggestions for DC and CONTENTdm Administrators}

While bepress and OCLC can make changes to improve accessibility, the administrators who configure or determine some of the settings in these systems can also help mitigate some of the issues encountered by the student in our study. Following are items that administrators should keep in mind as they work with DC and CDM.

\section{Digital Commons (DC)}

We have three suggestions for DC repository administrators.

1. Consider including conference schedules in an accessible Excel document for download. The student in our study commented,

If there's a way of having an Excel version tied to this or something like that, like "download schedule in Excel" that is kind of the most ideal because at that point you can use your arrow keys to go left and right and all through it. It's really easy to follow the layout of it in an Excel 
spreadsheet, a lot easier than it is to do it in a table on a web page (A. Page, personal communication, April 1, 2014).

Admittedly, creating the Excel schedule would require additional work; however, schedules from DC can be copied and pasted into an Excel document relatively easily. From there, administrators can "clean up" the document and ensure that it is accessible. Ryerson University provides an excellent tip sheet for creating accessible Excel documents (Ryerson University, 2014).

2. The text introducing the download button in a book gallery can be changed to accurately describe the kind of content that a user can expect to download when clicking the download button. When you upload non-textual items, such as oral histories or lectures, to a book gallery, consider asking bepress support to change the text from the default, "Download Full Text," to something more specific, such as "Download Audio Interview" or "Download Video Lecture."

The text on the download button itself can also be customized for the primary files of all the items in a single structure. This customization could be problematic in cases where a single structure/series includes different kinds of primary files (e.g., audio and video and text), but if you know that all of the primary files within a single structure will only include a single kind of content, such as video, you could ask for the text on the download button itself to say "Download Video."

3. Finally, we suggest that repository managers include adequate descriptive metadata, especially for non-textual items. The metadata in DC is very prominent and accessible to a screen-reader user, so make use of it. It can act as really rich "alternative text," particularly for images, audio, and video, providing users with context about the item and information about what kind of file(s) and what kind of materials are associated with an item. Even with fully searchable, text-based items, the metadata can give screen-reader users the context they need to decide whether or not an item is useful to them prior to download. 


\section{CONTENTdm}

We have several suggestions for CDM administrators.

1. We suggest that CDM administrators include adequate descriptive metadata. Please see our rationale for this suggestion as described above in item 3.

2. For image and non-OCR'd text collections, consider the title field carefully. The title stands in for traditional alternative text, so if you upload a photograph of Abraham Lincoln, it would be more useful for a screen reader user to hear "photograph of Abraham Lincoln" rather than "Abraham Lincoln." There is some debate in the accessibility community about using words like "photograph of" because it can sound redundant in some contexts; however, in the context of CDM, we think it would be useful. When the student is listening to titles in a results list, "photograph of Abraham Lincoln" would clarify the fact that "Abraham Lincoln" is the subject of the item, not the creator. Robinson (2004) makes an alternative suggestion regarding this latter example in her dissertation ( $p$. 26).

3. In CDM's web site configuration tool, you have options regarding the fields that display on searchresults pages. We suggest that you include the name of the digital collection as one of these fields. (This suggestion requires that you include a field for the name of the digital collection in your metadata.) When searching multiple collections within CDM, the inclusion of the name of the digital collection in the results list can help users determine the source(s) of the items. We believe this suggestion helps users regardless of whether or not they are using a screen reader. Dickson made the same suggestion in 2008 (p. 370).

4. Consider ordering your metadata fields so that the fields that best and most quickly identify the item are listed at the beginning of the metadata record. In many cases, the title and description will offer the most relevant identifying information the most immediately, but consider this suggestion 
on a collection-by-collection basis. Depending on the content and scope of the collection, you may want to list other fields at the top of the metadata record.

5. In CDM's website configuration tool, you have the option to enable or disable hyperlinked metadata. For accessibility, we recommend that you disable hyperlinked metadata. We hesitate to make this suggestion because hyperlinked metadata in CDM can be very useful as an additional search/browse tool for non-impaired users. However, similar to Southwell and Slater (2012), the student in our study encountered difficulties with hyperlinked item-level titles and descriptions because his screen reader announced "link" before each hyperlinked word. The result was that the item titles and descriptions were extremely difficult to understand, and he quickly lost interest in trying to parse the information. The result is that the hyperlinked metadata was functionally inaccessible.

6. If you choose not to disable hyperlinked metadata, we strongly encourage you to use CDM's controlled vocabulary feature at the field level, especially for fields that contain values that typically come from a controlled vocabulary, such as subjects, geographic locations, and time periods. Using a controlled vocabulary for a field results in controlled terms that display and act as single terms, regardless of the number of individual words they contain. When the student encountered a hyperlinked, multi-word, controlled term in a subject field, his screen reader announced "link" only once. Had the term not been controlled within CDM, the word "link" would have been announced before every individual hyperlinked word.

7. We recommend that you avoid use of the compound-object structure whenever possible. The student in our study found the compound-object structure to be poorly designed and difficult to navigate. He did not understand the content panel, which includes the table of contents for the pages in a compound object. The expandable table of contents menu did not work with his screen reader. 
We should note that as a result of this finding, we have uploaded multiple-page documents as non-compound object PDFs, even when the PDFs do not include typed text and cannot be processed by optical character recognition (OCR) software. When it came down to the decision between inaccessible PDFs and an inaccessible compound object structure, we decided in favor of the former. This decision is somewhat controversial and may not be the optimal solution. Lazar and colleagues (2007) found that image-only or otherwise inaccessible PDFs are among the leading causes of frustration for screen-reader users (p. 247). Similarly, Tatomir and Durrance (2010) emphasize the importance of accessible PDFs in their Tatomir Accessibility Checklist (TAC), a checklist that "distills the ten features that are key to accessibility for users of adaptive technologies" (p. 581). We would prefer to find a better solution to this dilemma.

\section{Conclusion}

Together, advances in technology, accessibility legislation, and social awareness around issues of accessibility have gone "a long way in allowing students with disabilities-even so-called 'severe' disabilities - to get an education and find meaningful work" (Stasio \& Campbell, 2013, para. 24). At least 1,200 students with disabilities are currently seeking a higher education at our institution (Disability Services for Students, n.d.). As more students with disabilities pursue college, and as more library collections are made available digitally, it is imperative that we work with software developers to make those digital resources accessible. Creating truly accessible digital collections is a complicated endeavor. The vast majority of the resources disseminated via systems such as DC and CDM are designed to be accessed visually. In spite of seemingly clear guidelines set out by legislation and the World Wide Web Consortium (W3C), a large portion of digital resources remains inaccessible for certain user communities. As our interview with a single student pointed out, digital collections CMSs can be technically compliant and still be functionally inaccessible. Differences among screen-reader functionality/capability; inconsistencies between various browser interactions with both the software 
platforms and screen readers; and differing user skill levels with available assistive technologies only add to the complexity. Add dwindling library budgets, fewer library staff, and a common reliance on proprietary (as opposed to open source) CMSs to this mix, and it is easy to see why institutions have difficulty creating truly accessible digital collections.

While apparently overwhelming, these complications should not stop collection administrators and software developers from addressing the issues various user studies continue to uncover. There are a number of things that can be done to improve the user experience. Creating clear and consistent contextual clues to aid in navigation and understanding of the content; configuring collections and utilizing the full functionality of CMSs with all users in mind; and continuing to explore how all user communities interact with digital collections will make a positive difference.

\section{Further Research}

The topic of accessible CMSs for digitized collections in libraries is ripe for further research. We would like to test the accessibility of DC and CDM after making some of the changes that we have suggested in this article. Further studies could include additional participants who use screen readers in order to determine how differing levels of ability and comfort with screen readers affects our understanding of the accessibility of these systems. It would be useful to conduct studies that explore the accessibility of the search capabilities within these systems. It would be instructive to test these systems with different screen readers to help determine if specific screen readers work more or less optimally or effectively with these systems. It would also be interesting to conduct studies on other content management systems that are used to host and make available digitized collections and institutional repository content, such as Luna Insight or DSpace. We would also like to learn more about how individuals with different kinds of impairments - aural, cognitive, and physical - interact with these systems. 


\section{References}

Ahmed, F., Borodin, Y., Puzis, Y., \& Ramakrishnan, I. V. (2012). Why read if you can skim: Towards enabling faster screen reading. Proceedings of the International Cross-Disciplinary Conference on Web Accessibility (pp. 39:1-39:10). New York, NY, USA: ACM. doi:10.1145/2207016.2207052

ARIA Landmarks. (n.d.). In Accessibility handbook. Raleigh, NC: NC State University. Retrieved from http://accessibility.oit.ncsu.edu/training/accessibility-handbook/aria-landmarks.html

Berkeley Electronic Press, (2011). Voluntary product accessibility template (VPAT). Digital Commons Reference Material and User Guides. Paper 21. Retrieved from http://digitalcommons.bepress.com/reference/21

Bigham, J. P., Cavender, A. C., Brudvik, J. T., Wobbrock, J. O., \& Lander, R. E. (2007). WebinSitu: A comparative analysis of blind and sighted browsing behavior. Proceedings of the 9th International ACM SIGACCESS Conference on Computers and Accessibility (pp. 51-58). New York, NY, USA: ACM. doi:10.1145/1296843.1296854

Byerley, S. L., Chambers, M., \& Thohira, M. (2007). Accessibility of web-based library databases: The vendors' perspectives in 2007. Library Hi Tech, 25(4), 509-527. doi:10.1108/07378830710840473

Cervone, H. F. (2013). Selected practices and tools for better accessibility in digital library projects. OCLC Systems \& Services: International Digital Library Perspectives, 29(3), 130-133. doi:10.1108/OCLC-05-2013-0015

Cooper, G. (1990). Cognitive load theory as an aid for instructional design. Australian Journal of Educational Technology, 6(2), p. 108-113. Retrieved from http://ascilite.org.au/ajet/ajet6 /cooper.html

Daniels, C. (2009). Providing online access to oral histories: A case study. OCLC Systems \& Services: International Digital Library Perspectives, 25(3), 175-185. doi:10.1108/10650750910982566 
Davies, J. E. (2007). An overview of international research into the library and information needs of visually impaired people. Library Trends, 55(4), 785-795. doi: 10.1353/lib.2007.0039

Dickson, Maggie. (2008). CONTENTdm digital collection management software and end-user efficacy. Journal of Web Librarianship, 2(2-3), p. 339-379. doi: 10.1080/19322900802190852

Disability Services for Students - University Of Montana. (n.d.). Retrieved September 22, 2014, from http://www.umt.edu/dss/

Fulton, C. (2011). Web accessibility, libraries, and the law. Information Technology \& Libraries, 30(1), 34-43. doi: 10.6017/ital.v30i1.3043

Goldstein, D. F. \& Niska, M. (2013, June). Why digital accessibility matters to the legal profession - A conversation with a young blind attorney. Law Practice Today. Retrieved from http://www.americanbar.org/content/newsletter/publications/law_practice_today_home /Ipt-archives/june13/why-digital-accessibility-matters-to-the-legal-profession.html

Hill, H. (2013). Disability and accessibility in the library and information science literature: A content analysis. Library \& Information Science Research, 35(2), 137-142. doi:10.1016/j.lisr.2012.11.002

Kahl, C. M., \& Williams, S. C. (2006). Accessing digital libraries: A study of ARL members' digital projects. The Journal of Academic Librarianship, 32(4), 364-369. doi:10.1016/j.acalib.2006.03.003

Kramer, E. F. (2005). IUPUI image collection: a usability survey. OCLC Systems \& Services: International digital library perspectives, 21(4), 346-359. doi: 10.1108/10650750510631712

Lazar, J., Allen, A., Kleinman, J., \& Malarkey, C. (2007). What frustrates screen reader users on the web: A study of 100 blind users. International Journal of Human-Computer Interaction, 22(3), p. 247269. doi: $10.1080 / 10447310709336964$

OCLC. (2011, September 15). Voluntary Product Accessibility Template (Version 6.1) Dublin, OH. Providenti, M., \& Zai, R. (2007). Web accessibility at academic libraries: Standards, legislation, and enforcement. Library Hi Tech, 25(4), 494-508. doi:10.1108/07378830710840455 
Riley, C.A. (2002) Libraries, aggregator databases, screen readers and clients with disabilities. Library Hi Tech, 20(2), 179-187. doi: 10.1108/07378830210432543

Robinson, A. (2004). The accessibility of digital image collections (unpublished master's thesis) University College London, London.

Ryerson University. (2014). Creating an accessible Microsoft Excel spreadsheet. Accessibility Tools \& Resources. Retrieved September 11, 2014 from: http://www.ryerson.ca/accessibility /tools/index.html

Schmetzke, A., \& Comeaux, D. (2009). Accessibility trends among academic library and library school web sites in the USA and Canada. Journal of Access Services, 6(1-2), 137-152. doi:10.1080/15367960802286286

Someren, M. W. van, Barnard, Y. F., \& Sandberg, J. (1994). The think aloud method: A practical guide to modelling cognitive processes. London; San Diego: Academic Press.

Southwell, K. L., \& Slater, J. (2012). Accessibility of digital special collections using screen readers. Library Hi Tech, 30(3), 457-471. doi:10.1108/07378831211266609

Stasio, F., \& Campbell, N. (2013, November 1). First deaf-blind student at Harvard law pursues dreams. The State of Things. Chapel Hill, North Carolina: WUNC. Retrieved from http://wunc.org/post/first-deaf-blind-student-harvard-law-pursues-dreams

Stewart, R., Schmetzke, A., \& Narenda, V. (2005). Accessibility and usability of online library databases. Library Hi Tech, 23(2), 265-286. doi:10.1108/07378830510605205

Tatomir, J., \& Durrance, J.C. (2010). Overcoming the information gap: Measuring the accessibility of library databases to adaptive technology users. Library Hi Tech, 28(4), p. 577-594. doi: $10.1108 / 07378831011096240$

Tatomir, J. \& Tatomir, J.C. (2012). Collection accessibility: A best practices guide for libraries and librarians. Chapter 5 in Library Technology Reports, 48(7), 36-42. 
Theofanos, M. F., \& Redish, J. (2006). Guidelines for accessible - and usable - web sites: Observing users who work with screenreaders. Interactions, 10(6), 38-51. Expanded "Authors' version" retrieved September 8, 2014 from www.redish.net/images/stories/PDF/InteractionsPaperAuthorsVer.pdf

UM/OCR Resolution Agreement, OCR Reference No. 10122118. (2014). Retrieved September 25, 2014 from http://www.umt.edu/accessibility/implementation/default.php

Valentino, M., \& Shults, B. (2012). Creating a digital library of three-dimensional objects in CONTENTdm. OCLC Systems \& Services: International Digital Library Perspectives, 28(4), 208-220. doi:10.1108/10650751211279148

Vigo, M., \& Harper, S. (2013). Challenging information foraging theory: Screen reader users are not always driven by information scent. Proceedings of the 24th ACM Conference on Hypertext and Social Media (pp. 60-68). New York, NY, USA: ACM. doi:10.1145/2481492.2481499

World Wide Web Consortium (W3C). (2008). Web content accessibility guidelines (WCAG) 2.0. Retrieved September 25, 2014, from http://www.w3.org/TR/WCAG20/\#guidelines

Xie, I., Babu, R., Jeong, W., Joo, S., \& Fuller, P. (2014). Blind users searching digital libraries: Types of help-seeking situations at the cognitive level. iSchools. doi:10.9776/14272 